\title{
Review: exercise programmes increase walking times in patients with intermittent claudication
}

\author{
Leng GC, Fowler B, Ernst E. Exercise for intermittent claudication. Cochrane Database Syst Rev 2000;(2):CD000990 (latest \\ version 23 January 2000).

\section{QUESTION: In patients with intermittent claudication (leg pain on walking), do exercise programmes increase walking times?}

\section{Data sources}

Randomised controlled trials were identified by using Medline, EMBASE/Excerpta Medica, handsearches of journals, bibliographies of reviews and identified trials, and contact with principal investigators of trials. The search strategy produced by the Cochrane Review Group on Peripheral Vascular Diseases was used.

\section{Study selection}

Trials were included if exercise programmes were compared with control or medical or surgical treatment; participants had self reported or clinically diagnosed intermittent claudication caused by atherosclerotic disease; the exercise programme included any form of leg physical activity (eg, walking or running); and outcomes were provided (treadmill walking distance, time to onset of pain, maximal walking distance, mortality, cardiovascular events, disease progression, indirect tests of disease such as ankle pressure measurements, and subjective measures such as symptom progression).

\section{Data extraction}

Data were extracted on study quality, exercise and control programmes including duration and intensity, patient numbers and characteristics, and outcomes including how they were measured.

\section{Main results}

10 trials (involving approximately 250 patients) met the inclusion and quality criteria. 3 trials compared exercise with placebo tablets, 3 trials used normal activity as the control programme, 2 trials compared exercise with drugs (antiplatelet agents and pentoxifylline), and 2 compared exercise with arterial reconstruction surgery

Weighted mean differences in walking times for patients with intermittent claudication who participated in exercise programmes

\begin{tabular}{lll} 
Comparison & $\begin{array}{l}\text { No of } \\
\text { studies }\end{array}$ & $\begin{array}{l}\text { Weighted mean } \\
\text { difference in walking } \\
\text { times in minutes }(95 \% \mathrm{Cl})\end{array}$ \\
$\begin{array}{l}\text { Exercise } v \text { usual care } \\
\text { or placebo }\end{array}$ & $3^{*}$ & $6.52(4.38$ to 8.67$)$ \\
\hline Exercise $v$ angioplasty & 1 & $3.30(2.21$ to 4.39$)$ \\
\hline $\begin{array}{c}\text { Exercise } v \text { antiplatelet } \\
\text { treatment }\end{array}$ & 1 & $1.06(0.15$ to 1.97$)$ \\
\hline Exercise $v$ surgery & 1 & $-1.66(-4.55$ to 1.23$) \dagger$ \\
\hline Exercise $v$ pentoxifylline & 1 & $-0.45(-0.66$ to -0.24$)$ \\
\hline
\end{tabular}

* 3 trials were not included in the statistical analysis because of incomplete data. †Not significant. or angioplasty. All programmes recommended $\geqslant 2$ sessions of exercise per week. Duration of the programmes was 3-12 months, and follow up ranged from 12 weeks to 15 months. Exercise increased walking times compared with usual care or placebo, angioplasty, and antiplatelet therapy. Pentoxifylline was better than exercise for walking times in 1 small trial, and no difference was shown between exercise and surgery (table).

\section{Conclusion}

Exercise programmes for patients with intermittent claudication generally improve walking times.
Sources of funding: Department of Health, The Scottish Office UK and The British Heart Foundation UK.

For correspondence: Dr G C Leng, Primary Care and Population Sciences, Royal Free and University College Medical School, Royal Free Campus, Rowland Hill Street, London

NW3 2 PF, UK. Fax +44 (0)207 7941224 .

\section{COMMENTARY}

It is estimated that more than 12 million people have peripheral arterial disease, ${ }^{1}$ and approximately half of these have intermittent claudication. Although many people have these conditions, relatively little attention has focused on the resulting disability. The review by Leng et al summarises the best literature on treating intermittent claudication with exercise programmes, an intervention that has been shown to effectively reduce the disability of intermittent claudication.

This high quality systematic review provides a clear description of the methods used for the selection of trials. Data were independently extracted by 2 reviewers. One area that should receive more attention is the effect of exercise programmes on health related quality of life. This issue is important to patients and is an important marker of efficacy.

The results are relevant to nurses who work in cardiac rehabilitation settings and those who are specialists in vascular and cardiovascular areas. Peripheral artery disease causes functional disability and patients may be unable to complete normal daily activities. As the population ages, the prevalence of intermittent claudication is likely to increase. More effort should be directed toward providing interventions that will help to alleviate symptoms and improve functional ability in patients with this condition. Questions that arise from the Leng review and that provide opportunity for further research are: (1) what is the sustainability of the observed changes after the intervention ends? (2) Is a home based programme as effective? And, (3) what is the effect of walking success on patient self efficacy and long term behaviour change? The ability of nurses to recognise peripheral artery disease, to acknowledge its associated disability, and to understand the efficacy of well structured exercise rehabilitation programmes will improve care and promote patient wellbeing.

Judith G Regensteiner, PhD Associate Professor of Medicine University of Colorado Health Sciences Center Denver, Colorado, USA

Diane Treat-Jacobson, RN, PhD Program Coordinator Minnesota Vascular Diseases Center University of Minnesota

Minneapolis, Minnesota, USA

1 Criqui MH, Fronek A, Barrett-Connor E, et al. The prevalence of peripheral arterial disease in a defined population. Circulation 1985;71:510-5. 